\title{
Avaliação da exposição a metais numa oficina de recuperação de armamento de uma organização militar
}

\author{
Exposure assessment to metals in an armament repair shop \\ of a military organization
}

Eduardo Borba N eves ${ }^{1,2}$

Nelson M endonça Junior ${ }^{1}$

M aria deFátima Ramos M oreira ${ }^{2}$

${ }^{1}$ Escola de Aperfeiçoamento de Oficiais do Exército. Av. Duque de Caxias 2947, Vila Militar. 21615-220 Rio de Janeiro RJ.

borbaneves@hotmail.com.

${ }^{2}$ Laboratório de

Toxicologia, Centro de

Estudos da Saúde do

Trabalhador eEcologia

Humana, Escola Nacional

deSaúde Pública Sergio

Arouca, Fundação O swaldo

Cruz.
Abstract The aim of this study was the occupational exposure assessment to lead and manganese of workers in an armament repair shop of a military organization. The air of the working environment was assessed in the environmental monitoring while the internal dose biological indicators for lead and manganese, in blood and urine, were used in biological monitoring. M etals concentration in filters and biological fluids were determined by electrothermal atomic absorption spectrometry. The results of the environmental monitoring showed lead and manganese levels above the TLV-TWA during the process of painting ( $313.33 \mathrm{gm}-3$ ) and solder ( $951 \mu \mathrm{g}$ $\mathrm{m}-3)$. The biological indicators revealed that five of the nine employees presented $\mathrm{Pb}$-S levels that suggested an environmental exposureto lead (values between 5 and $10 \mu \mathrm{gdL}-1$ ). It can be concluded that there is a small occupational exposure to lead and manganese in the superficial treatment repair shop. This exposureis influenced by weather conditions and the variable demand of work. Key words Lead, M anganese, Air, Blood, U rine, Exposureassessment
Resumo 0 objetivo desteestudo foi a avaliação da exposição ocupacional ao chumbo e manganês dos trabalhadores de uma oficina de recuperação de armamento de uma organização militar. 0 ar do ambiente de trabalho foi avaliado no monitoramento ambiental e os indicadores biológicos de dose interna, para chumbo emanganês, em sangueena urina, foram utilizados no monitoramento biológico. A concentração de manganês e chumbo nos filtros e flui dos biológicos foi determinada por espectrometria de absorção atômica eletrotérmica. Os resultados do monitoramento ambiental indicaram níveis de $\mathrm{Pb}$ e $\mathrm{Mn}$ acima do TLV-TWA durante o processo de pintura $\left(313,33 \mu \mathrm{g} \mathrm{m}^{-3}\right)$ e solda ( $\left.951 \mu \mathrm{g} \mathrm{m}^{-3}\right)$. Os indicadores biológicos revelaram que cinco dos nove trabal hadores apresentam níveis de $\mathrm{Pb}$-S quesugerem exposição ambiental ao chumbo (valores entre 5 e $10 \mu \mathrm{g} \mathrm{dL}^{-1}$ ). Podeseconcluir queexisteuma pequena exposição ocupacional ao chumbo e ao manganês na oficina de tratamento superficial. Tal exposição é influenciada pelas condições meteorológicas e pela demanda variável de trabalho.

Palavras-chave Chumbo, Manganês, Ar, Sangue, U rina, Avaliação da exposição 
Introdução

A partir da década de setenta, houve um aumento do interesse sobre as relações de trabal ho com a saúde do trabalhador. 0 crescimento da produção científica fez com que fossem reconhecidas as situações de risco presentes nos ambientes de trabalho $0^{1-3}$.

As pequenas indústrias queutilizam substâncias químicas empregam, em geral, perto de dez trabal hadores, caracterizados por possuírem baixa escolaridade e nenhum tipo de treinamento e informações quanto aos riscos e às atitudes de proteção e segurança que deveriam ser tomadas. Suas instalações são inadequadas e utilizam um processo de trabalho simples e arcaico, provocando a contaminação por produtos químicos não apenas dos trabalhadores, mas atingindo também as áreas em torno e populações circunvizinhas4.

Entre as diversas classes de trabal hadores investigados, a dos militares brasileiros éumas das com menor expressão na literatura científica ${ }^{5}$. Alguns estudos com militares americanos suge rem que essa classe pode estar exposta a substâncias tóxicas ou radioativas $5^{6-8}$.

Pode-se encontrar na literatura estudos de exposição à hexacloretano ${ }^{7}$, em militares americanos; manganês, cobre, cádmio, zinco e chumbo, em soldadores ${ }^{9}$; urânio empobrecido, em militares que atuaram pela Organização das Nações Unidas (ONU) no conflito da Bósnia8; ruídos, em militares brasileiros e da força aérea finlândesa ${ }^{10,11}$; e chumbo, em atividades de remoção e decapagem de tintas, em trabalhadores de diversas profissões ${ }^{12-14}$, inclusive militares da força aérea dos Estados Unidos ${ }^{15}$.

As oficinas de tratamento superficial existentes nas organizações militares de manutenção do Exército Brasileiro têm o porte de uma pequena indústria, cujo principal objetivo éa realização de pequenos reparos que exijam soldas e restauração de superfícies metálicas. 0 tratamento superficial visa conferir, às peças prontas, um acabamento que impeça a ação da atmosfera corrosiva, através da formação de uma película protetora sobre a superfície do metal ${ }^{16}$. Entre outros métodos, utiliza-se a eletrodeposição de metais, que aumenta a resistência à corrosão, ao desgaste e às altas temperaturas, bem como a diminuição do coeficiente de atrito e outras propriedades ${ }^{17}$.

A utilização de produtos químicos e a geração de resíduos tóxicos durante o tratamento superficial faz desteum processo potencialmente insalubre ${ }^{16}$. N este sentido, torna-se necessário a avaliação da exposição dos trabalhadores, relacionando as etapas desenvolvidas durante a recuperação dos armamentos com o ambiente de trabalho e saúde do trabalhador.

Assim, o objetivo deste estudo foi a avaliação da exposição ocupacional dos trabalhadores da oficina de tratamento superficial de armamento de uma organização militar ao chumbo e ao manganês. 0 tratamento superficial de armamento éa fase final da recuperação (repotencialização) do armamento que, por vezes, é precedido por algum pequeno reparo envolvendo solda. 0 ar do ambiente de trabal ho foi avaliado no monitoramento ambiental, enquanto que 0 chumbo e o manganês, ambos em sangue e urina, foram os indicadores utilizados no monitoramento biológico.

\section{Manganês}

0 manganês ( $\mathrm{Mn}$ ) é um elemento existente em abundância na crosta terrestre, água e atmosfera, na forma particulada. Também está presente em minérios como o de ferro e pode ser amplamente encontrado em diversos tipos de rochas ${ }^{18}$.

Este elemento tem diversas aplicações industriais, sendo que $90 \%$ da demanda total de manganês são utilizados na produção de aço. Além disso, este metal e seus compostos são usados na galvanoplastia, fabricação de varetas para soldas, produção de baterias, porcelanas e materiais à base de vidros. Também encontram aplicação na indústria de cerâmica para colorir vidros, na fabricação de corantes, tintas, vernizes, secantes e produtos farmacêuticos. Outros compostos de manganês são usados como catalisador, suprimento para animais, fertilizante e fungicida, entre outros ${ }^{18}$.

A absorção do manganês ocorre primeiramente por via oral e inalação, pelo trato gastrintestinal após ingestão e no epitélio alveolar após inalação. Parte do manganês inalado também pode ser engolido com muco e, assim, ser absorvido pelo trato gastrintestinal. A absorção neste local éinfluenciada por diversosfatores, taiscomo presença de ferro na dieta, tipo de composto introduzido, idade eingestão concomitante de bebidas al coólicas ${ }^{19}$.

0 manganês é distribuído para todas as células do organismo. No sangue, se encontra ligado, em grande parte, às proteínas plasmáticas e de 0,5 a $9 \%$ provavelmente à porfirina nos eritrócitos ${ }^{20}$. Os locais que apresentam as maiores concentrações do metal no organismo são os de 
maior atividade metabólica, como o fígado e pâncreas, eaqueles ligados à eliminação como os rins e intestinos. Por outro lado, os tecidos de baixa atividademetabólica, como músculos, pele, bexiga, testículos, útero, ossos e tireóide apresentam menores níveis. Esta distribuição provavelmente está correlacionada com a quantidade de mitocôndrias do órgão ou tecido ${ }^{18}$.

A concentração de manganês nos diferentes sítios é estável ao longo da vida, não se alterando com a idade e seus valores são considerados característicos do tecido ou órgão, independentemente da espécie animal. Os tecidos pigmentados, como o cabelo ea pele, se escuros, tendem a acumular manganês. Este metal penetra nas barreiras hematoencefálica e placentária e pode ser secretado no leite materno ${ }^{20}$.

Os íns do metal são quase que totalmente excretados através da bile nas fezes e muito pouco manganês é eliminado na urina ${ }^{19}$. A excreção biliar é considerada como um mecanismo regulador na manutenção de um conteúdo estável desteelemento nos tecidos. 0 manganês tem uma meia-vida biológica pequena (média de 36 dias para todo organismo), que depende da quantidade ingerida e dos suprimentos de manganês no organismo. A eliminação inclui uma primeira fase rápida com duração de quatro dias, seguida por um período mais longo (aproximadamente 39 dias) de excreção lenta. Acredita-se que essas fases reflitam dois tipos de ligação do manganês no organismo ${ }^{18,19}$.

O manganês é um elemento essencial ao homem ea dieta éa principal fontedo metal para as pessoas não expostas ocupacionalmente. Este metal desempenha um papel importanteno processo de formação de ossos e tecidos, funções reprodutivas e no metabolismo de carboidratos e lipídios. Entretanto, em níveis elevados, como aqueles encontrados nos ambientes de trabalho, é um elemento neurotóxico ${ }^{21}$.

O sistema nervoso central (SNC), exposição aguda e crônica, e os pulmões (exposição aguda) são os órgãos críticos na ação tóxica do manganês. A toxicidade para o cérebro semanifesta como uma desordem crônica do SNC parecida com a doença de Parkinson, enquanto que uma maior susceptibilidade para bronquite ou, em casos mais sérios, pneumonia se revela como um efeito crítico do metal nos pulmões ${ }^{19}$.

Os indicadores biológicos utilizados para a avaliação da exposição ao manganês não são inteiramentesatisfatórios, uma vez quenão há uma relação razoável entre a exposição ao metal, níveis biológicos do manganês e a intensidade dos efeitos. Esta incerteza provavelmenteéo resultado da movimentação relativamente rápida de manganês absorvido em contraste com a progressão lenta da doença ${ }^{19}$.

0 monitoramento do manganês no sangue e na urina auxilia na confirmação da exposição ao metal, mas não se correlaciona com exposição passada ou intoxicação crônica pelo metal. Entretanto, podeser realizado desdequea interpretação dos dados seja extremamente criteriosa, em virtude da ampla variação interindividual ${ }^{18}$. Os resultados da determinação da concentração de manganês em sangue e urina não provam que seus níveis nestes meios biológicos possam contribuir para a avaliação correta do grau de exposição individual de baixo nível. As diferenças (se algumas) entre os valores encontrados em indivíduos expostos e não expostos são mínimas e podem ser usadas somente como um teste de grupo ${ }^{18}$.

A Norma Regulamentadora no 7 (NR-7) não cita o manganês, entretanto, de acordo com uma pesquisa desenvolvida na comunidadeeuropéia ${ }^{22}$, a concentração média demanganês no sanguede adultos não expostos é de $8,8 \pm 0,2 \mathrm{mg} \mathrm{L}^{-1}$, enquanto que, na urina, o intervalo encontrado foi de 0,12 a 1,9 mg M n L-1, com a média em 1,02 \pm $0,05 \mathrm{mg} \mathrm{L}^{-1}$.

$O$ threshold limit value (TLV) - time weighted average (TWA) para manganês na American Conference of Governmental Industrial H ygienists (ACGIH) éde $0,2 \mathrm{mg} \mathrm{m}^{-3}$. A N orma Regulamentadora no 15 (N R-15) não cita o manganês, porém indica o uso do limite da ACGIH quando este não existir na mesma²1.

\section{Chumbo}

0 chumbo( $\mathrm{Pb}$ ) éum elemento deocorrência natural, encontrado em relativa abundância na crosta terrestre. As suas principais fontes naturais incluem as emissões vulcânicas, o intemperismo das rochas e as emissões provenientes do mar. No entanto, devido à intensa exploração deste metal pelo homem, atualmenteé difícil avaliar o conteúdo de chumbo originário dessas fontes naturais, uma vez queéo metal mais abundanteno ambiente ${ }^{23}$.

Atualmente, as maiores fontes ambientais de chumbo e seus sais, que contribuem para a ingestão diária, são ar, poeira, alimentos, bebidas e tinta. A fumaça de cigarro também pode aumentar o total de chumbo ingerido por dia. A ingestão de tintas que contêm chumbo se constitui na 
maior fonte disponível do metal para crianças e importante fonte para muitos adultos, especialmente aqueles envolvidos com construção e reforma de casas, e os que têm a pintura como profissão ou passatempo ${ }^{24}$.

Embora seja um dos contaminantes ambientais mais comuns, o chumbo não possui ne nhuma função fisiológica conhecida no organismo e seus efeitos nocivos podem afetar praticamente todos os órgãos e sistemas do corpo humano. A principal forma de entrada do chumbo no corpo dá-se principalmente pela via respiratória (importante rota na exposição ocupacional), seguida da via digestiva, predominante para a população em geral. Somente os compostos orgânicos de chumbo penetram ao contato com a pele íntegra, sendo absorvidos rapidamente ${ }^{25}$.

A absorção do chumbo no organismo é influenciada pela rota de exposição, forma química da espécie contaminante, tamanho da partícula (no caso de particulado), solubilidade em água e variações individuais fisiológicas e patológicas. Essa absorção no sangue pode ser superior a 50\% da dose inal ada/ingerida para gases de exaustão e sais altamente solúveis, assim como para fumantes e pessoas com doenças das vias respiratórias superiores. Por outro lado, a absorção do metal pelo trato gastrintestinal varia de 2 a $16 \%$, seinge rido com refeição, mas pode chegar a $60-80 \%$, quando administrado em jejum. Mulheres grávidas e crianças absorvem 45 a $50 \%$ do chumbo presente na dieta. Os fatores da nutrição, tais como estado fortificado, ingestão de cálcio, ferro, fósforo e proteínas são mais importantes para a absorção do metal por esta via do que a solubilidade dos compostos de chumbo devido à acidez estomacal. A deficiência destes nutrientes aumenta a absorção do chumbo e vice-versa ${ }^{23}$.

A pós ser absorvido, o chumbo é distribuído por todo organismo pelo sangue. A distribuição do chumbo no organismo depende da sua taxa de transferência da corrente sanguínea para os diferentesórgãosetecidos. U mavez absorvido, o chumbo segue uma cinética complexa no organismo, se distribuindo entreo sangue, tecidos moles emineralizados. Os ossos contêm cerca de 90 a $95 \%$ do total do conteúdo corpóreo de chumbo em adultose 80 a $95 \%$ em crianças. 0 chumbo tem tempos demeia-vida distintos, sendo de 36 dias no sangue. Já a meia-vida do metal nos tecidos moles é de aproximadamente quarenta dias, enquanto que, nos ossos, este tempo é de cerca de 27 anos $^{25}$.

Embora a concentração de chumbo no sangue $(\mathrm{Pb}-\mathrm{S})$ seja menor do que $2 \%$ do seu total no corpo, neste compartimento, de $90-99,8 \%$ do metal estão ligados às membranas ou frações de proteínas das células vermelhas e cerca de, 0,2 a $10 \%$ do $\mathrm{Pb}-\mathrm{S}$ se situa no plasma, representando a fração lábil ebiologicamente ativa do chumbo, capaz de cruzar as membranas celulares e causar seus efeitos tóxicos ${ }^{23}$.

0 chumbo é excretado por várias rotas; porém, só a excreção renal ea gastrintestinal são de importância prática. A quantidadeexcretada, independenteda rota, éafetada pela idade, características da exposição e dependente da espécie. 0 chumbo absorvido é excretado principalmente pela urina ( $75-80 \%$ ), cerca de $15 \%$ pelas fezes, e outras possíveis rotas de eliminação são suor, descamação cutânea, cabelo eunhas (<8\%). Uma forma especial de excreção do chumbo endógeno, mas de pouca importância do ponto de vista de liberação do organismo, é através do leite materno. No entanto, estetipo deeliminação pode representar um risco para o lactente, já que existe uma correlação en tre as concentrações do chumbo no sangue e leite. Baixos níveis de chumbo têm sido encontrados no sêmen de homens sem exposição específica ${ }^{24}$.

Os efeitos biológicos do chumbo são os mesmos quaisquer que sejam as rotas de entrada, uma vez que há interferência no funcionamento normal da célula e em inúmeros processos fisiológicos. Apesar dos ossos serem os maiores depósitos de chumbo, os primeiros efeitos adversos não são aí observados e sim no sistema nervoso, medula óssea e rins, tidos como órgãos críticos na exposição ao chumbo, enquanto que os distúrbios na função do sistema nervoso (SN) e os desvios na síntese do heme são considerados como efeitos tóxicos críticos $^{26}$.

Inúmeros testes mostram a ocorrência de exposição ao chumbo, que pode ser determinado em sangue, urina, tecidos moles, ossos e dentes. Apesar dos indicadores de dose interna, tais como sangue total, plasma eurina, e os de efeito, ácido delta aminolevulínico na urina (ALA-U), ácido delta aminolevulínico desidratase (ALAD), zinco protoporfirina (ZPP) e protoporfirina eritrocitária (PE), serem muito utilizados, todostêm algum tipo de limitação. Por isso, a concentração dechumbo no sangue total éaceita como indicador de exposição total a este elemento, embora indique uma exposição recente ${ }^{24}$.

Osíndices biológicos permitidos para chumbo na NR-7, Portaria № 24/1994 do Ministério do Trabalho, são os mesmos fixados pela ACGIH nos Estados Unidos em 1972, baseados no conhecimento científico vigente na época. Contudo, uma pesquisa ${ }^{27}$ realizada em Londrina (PR) 
recomenda a redução do índice biológico de exposição para chumbo em sangue para $32 \mu \mathrm{g} \mathrm{dL}^{-1}$, o que é compatível com o valor recomendado pela ACGIH em 1998, $30 \mu \mathrm{g} \mathrm{dL}^{-1}$. Entretanto, esses val ores devem ser reavaliados na medida em que novos dados estiverem disponíveis ${ }^{28}$.

Também o limite de tolerância para chumbo no ar, 0,1 $\mathrm{mg} \mathrm{m}^{-3}$, estabelecido pela Norma Regulamentadora no 15 (NR 15), Portaria no 12/1983 do M inistério do Trabalho, éo dobro daquele pre conizado pela ACGIH, 0,05 $\mathrm{mg} \mathrm{m}^{-3}$, para que a maioria dos trabalhadores possa ser exposta sem efeitos adversos, durante jornada de quarenta horas semanais e oito horas de trabalho por dia ${ }^{29}$.

De acordo com a N orma Reguladora no 7 (Portaria no 24, de 29 de dezembro de 1994 da Secretaria de Segurança e Saúde no Trabalho), níveis de chumbo em sangue iguais à $40 \mu \mathrm{g} \mathrm{dL}^{-1}$ são considerados valores de referência para 0 metal no organismo humano ${ }^{30}$. Uma pesquisa realizada na Itália encontrou, após monitoramento biológico, concentrações de chumbo no sangue até $27,6 \mu \mathrm{g} \mathrm{dL}^{-1}$, enquanto que os teores de chumbo na urina ficaram em $2,7 \mu \mathrm{g} \mathrm{dL}^{-1}$, em pessoas não expostas ocupacionalmente ${ }^{22}$.

\section{Tratamento de superfície}

0 tratamento de superfície pode ser descrito como uma sequência de banhos com produtos químicos a que as peças metálicas são submetidas dentro de tanques específicos, e de uma decapagem física da superfície, que aconteceu por jateamento com microesferas de vidro, no caso da organização militar em estudo. 0 conjunto de tanques dispostos na sequência dos banhos é chamado delinha detratamento superficial. N estes tanques, as peças são submersas nos banhos químicos para que a camada protetora deposite-se sobre a superfíciemetálica ${ }^{31}$. D estacam-sea fosfatização e a oxidação entre os tratamentos superficiais utilizados antes do recebimento da pintura final ou oleamento.

O fosfato de manganês, o ácido sulfúrico, a soda cáustica, o óleo protetivo, o ácido muriático e as tintas são os principais produtos químicos utilizados em tratamentos de superfície. Os resíduos gerados são de natureza sólida, líquida e gasosa, constituídos principalmente de chumbo, níquel, cádmio, manganês ezinco ${ }^{16}$. No processo de fosfatização, o manganês está presente como reagente nos banhos à base de fosfato de manganês, enquanto o chumbo aparece, essencialmente, como componente das tintas.

\section{Parte experimental}

\section{Área de estudo e população}

A penas al gumas organizações militares estão capacitadas para realizar o processo detratamento superficial de armamentos. No Exército Brasileiro, estas organizações militares são os arsenais de guerra, parques regionais de manutenção e o batalhão de manutenção de armamento ${ }^{16}$. O Arsenal de Guerra do Rio de Janeiro foi 0 escolhido por se localizar dentro desse município, pela demanda de produção expressiva e por ser a organização militar que possui o maior número de trabalhadores nesse setor.

A coleta de dados foi realizada durante o mês de maio de 2006, em visita única ao local de trabalho. Todos os trabalhadores da oficina de tratamento de superficial aceitaram participar do estudo (monitoramento biológico e monitoramento ambiental do ar), das entrevistas (anamnese ocupacional) e, ainda, preencher e assinar os termos de consentimento livre e esclarecido, de acordo com a Resolução n 196/96 do ConseIho Nacional de Saúde.

Foram coletadas amostras de sangue e urina de todos os trabal hadores (nove sujeitos do sexo masculino) e, após isso, dois trabal hadores realizaram a sequência de atividades de tratamento superficial do armamento para coleta das amostras de traços no ar, visando ao monitoramento ambiental. Destes, apenas um realizou a atividade de solda.

\section{Processo de trabalho}

Inicialmente, as peças passam por um desengraxe, através de um banho alcalino com soda cáustica; a seguir, são levadas para uma cabine, ondesão jateadas com microesferas de vidro, para a remoção completa do tratamento superficial anterior. D epois seguem para a fosfatização, onde passam por uma sequência de banhos com fosfato de manganês para deposição da camada protetora. Por último, são pintadas com o prime e, depois, com tinta a óleo.

$\mathrm{Na}$ atividade de pintura, um dos trabal hadores (Trabalhador 1) utilizou a tinta prime, enquanto que o outro (Trabalhador 2) atuou com tinta a óleo. A solda foi realizada com eletrodo composto por $0,07 \%$ carbono, 0,5\% silício e 1,3 $\%$ manganês. 
Instrumental

O sistema de coleta do ar do ambiente de trabalho foi constituído por uma bomba aspirante portátil, modelo 224-PCXR8 (SKC - Eighty Four, PA USA), com vazão calibrada para 2,0 L $\mathrm{min}^{-1}$; suporte para filtro, filtro de éster celulose de $37 \mathrm{~mm}$ de diâmetro e poro de $0,8 \mathrm{~mm}$, M illipore (USA); tubo de látex e cassete (SKC).

Um espectrômetro de absorção atômica Zeeman 5100, equipado com um programador forno de grafite HGA-600 e um amostrador automático As-60, todos Perkin-Elmer (Norwalk, CT USA), foram utilizados neste trabalho, além de tubos recobertos com grafite pirolítico e plataforma de grafite pirolítico (Perkin-Elmer). 0 comprimento deonda da lâmpada de catodo oco (Perkin-Elmer) de chumbo é de 283,3 nm, enquanto que $279,5 \mathrm{~nm}$ é para manganês. A largura da fenda é de 0,7 e 0,2 nm para chumbo e manganês, respectivamente. A avaliação do sinal corrigido Zeeman foi realizada por medidas de absorvância integrada (área de pico).

M ateriais, reagentes

e amostras dos fluidos biológicos

Todo material plástico evidraria utilizadosficaram imersos por um período mínimo de 24 horasem solução de Extran (M erck, Elmsford, USA) a $5 \%(v / v)$, enxaguadosabundantementeem água corrente e novamente imersos por, pelo menos, 48horasem solução deácido nítrico (M erck) 10\% (v/v), para descontaminação. Em seguida, foram lavados copiosamente com água ul trapura do tipo M illi-Q (M illipore, Bedford, USA) e secos à 40 C em estufa. Até o uso, o material deve ser guardado devidamente protegido de contato com superfícies metálicas e de poeira ${ }^{24}$.

Todos os reagentes utilizados foram, pelo menos, de grau analítico (PA). O s padrões eram preparados diariamente por diluições apropriadas das soluções estoque de $1000 \mathrm{mg} \mathrm{mL}^{-1}$ de chumbo e de manganês ( $M$ erck) em ácido nítrico 0,2\% (v/v), usando-se água previamente purificada em sistema M illi-Q (Millipore) para as diluições.

Na preparação do modificador, foi utilizada uma mistura de nitrato de magnésio $10 \mathrm{~g} \mathrm{~L}^{-1} \mathrm{e}$ nitrato de paládio $10 \mathrm{gL}^{-1}$, também M erck, diluída em ácido nítrico 0,2\% (v/v), de modo a conter $10 \mu \mathrm{g}$ de $\mathrm{Mg}\left(\mathrm{NO}_{3}\right)_{2}$ e 15 mg de Pd metálico em $10 \mu \mathrm{L}$ de solução dentro do forno.

0 sangue total foi diluído em Triton X-100 0,1\% (v/v) (M erck) na proporção de 1+9 para a determinação de $\mathrm{Pb}$, enquanto que uma diluição de quatro vezes foi utilizada no caso do $\mathrm{Mn}$. Já a urina foi diluída 1+4 e1+1 em ácido nítrico 0,2\% (v/v) para chumbo e manganês, respectivamente.

Os filtros de éster celulose foram colocados em frascos de polietileno, dissolvidos em $2 \mathrm{~mL}$ de ácido nítrico concentrado, por 1-2 horas à temperatura ambiente, e solubilizados com 48 $\mathrm{mL}$ de água deionizada. Uma alíquota desta solução ér retirada e diluída convenientemente.

A exatidão dos resultados foi acompanhada por meio da análise, em cada série de amostras, dos seguintes materiais de referência, diluídos conforme sua concentração:

- Contox Trace Metal Serum Control (144 1097RO 2 Level I, Kaulson Laboratories, USA): $16 \pm 4 \mu g \mathrm{~L}^{-1}(\mathrm{Mn})$;

. Contox Blood Lead Controls (Kaulson Laboratories, USA): $5 \pm 3 \mu \mathrm{gdL}^{-1}$ (LBO33RO2, Low Level), $25 \pm 4 \mu \mathrm{g} \mathrm{dL}^{-1}$ (M B30RE02, M edium Level);

- Lyphochek Urine Metals Control Level 2 (BIO-RAD, USA): $19,9 \pm 4,0 \mu \mathrm{gL}^{-1}(\mathrm{Mn})$ e $72 \pm$ $14,5 \mu \mathrm{gL}-1(\mathrm{~Pb})$;

. Metals on Filter Media SRM 2676d IIId (NIST, USA ): 19,83 $\pm 0,38 \mu_{\text {g }}$ filter $^{-1}(\mathrm{M} \mathrm{n})$ e 29,77 $\pm 0,61 \mu$ filter $^{-1}(\mathrm{~Pb})$.

\section{Amostragem do ar}

0 método de amostragem pessoal foi utilizado na avaliação da exposi ção individual a metais. 0 ar foi coletado próximo à área respiratória do trabalhador, por meio de filtros de éstercelulose, a fim de estimar a concentração dos metais inalados por este. Assim, com as bombas fixadas à cintura e cassetes presos à lapela, dois trabalhadores realizaram as atividades necessárias para a recuperação de armamentos.

O tempo de coleta em cada posto de trabalho foi definido pelo próprio trabalhador, orientado para realizar os procedimentos de forma natural, procurando retratar, da melhor forma possível, a rotina de trabalho do setor. Após cada atividade, o cassete era cuidadosamente desconectado, lacrado e guardado, em caixa apropriada, até o seu preparo no laboratório.

\section{Resultadosediscussão}

Osindivíduos foram caracterizados pela média e respectivos desvios padrão das seguintes variáveis: idade (anos) - 41,8 + 18,0; peso ( $\mathrm{kg})$ - 74,4 $\pm 10,7$; altura $(\mathrm{m})-1,70 \pm 0,06$ etempo de servi- 
ço na oficina (anos) - 9,8 $\pm 9,4$. Durante o monitoramento ambiental, as condições climáticas dentro da oficina eram as seguintes: boa ventilação, $28,4^{\circ} \mathrm{C}$ de temperatura e $64 \%$ de umidade relativa do ar.

Todosossujeitos relataram usar regularmente os equipamentos de proteção individual (EPI) durante a realização das suas tarefas na oficina; porém, há relatos de que o uso de máscaras em dias quentes é muito incômodo eque, nos trabaIhos de pequena monta, o uso de EPI éignorado. Durante a coleta das amostras, não se observou a utilização de qualquer equipamento de prote ção individual pelos trabalhadores.

Observou-se que, durante o processo de tratamento superficial existentena oficina, a temperatura do fosfato de manganês utilizado como reagente no banho das peças variava de $75{ }^{\circ} \mathrm{C}$ a 95으, dependendo das especificações do fabricante, gerando vapores tóxicos facilmente inalados pelo trabalhador. Como não existem exaustores instalados sobre a linha de tanques, todos os operários desta unidade de trabal ho estão expostos aos vapores tóxicos e não apenas aqueles que exercem a atividade num determinado momento. No entanto, relatam que só se aproximam dos tanques de banho em casos estritamente necessários, apesar do local ser relativamente pequeno e com os postos de trabalho muito próximos.
A legislação brasileira recomenda o uso dos limites da American Conference of Governmental Industrial Hygienists (ACGIH) no caso destes não constarem das normas regulamentadoras ou, ainda, quando forem maiores do que aqueles estabelecidos pela conferência americana. Assim, na interpretação dos resultados de manganês e chumbo no ar, utilizou-se os valores de 200 e 50 $\mu \mathrm{g} \mathrm{m}^{-3}$, respectivamente, para TLV-TWA ${ }^{32,33}$ preconizados pela ACGIH . A NR-1529, da legislação brasileira, não estabelecelimite detolerância para o manganêse, no caso do chumbo, este valor éo dobro ( $100 \mu \mathrm{g} \mathrm{m}^{-3}$ para até $48 \mathrm{~h}$ semanais de trabalho) daquele estabelecido pelos higienistas industriais americanos.

De acordo com a N R-15, limite de tolerância é a concentração ou intensidade máxima ou mínima, relacionada com a natureza e o tempo de exposição ao agente, quenão causará dano à saúde do trabalhador, durante a sua vida laboral ${ }^{29}$. Por outro lado, o Threshold Limit Value - Time Weighted Average (TLV-TWA) publicado pela ACGIH se define como a concentração média ponderada pelo tempo para uma jornada normal de oito horas diárias e quarenta horas semanais, à qual a maioria dos trabalhadores pode estar repetidamente exposta, dia após dia, sem sofrer efeitos adversos à saúde ${ }^{21}$. A Tabela 2 apresenta os resultados encontrados no monitoramento do ar do ambiente de trabalho.

\begin{tabular}{lcc}
\hline Tabela 1. Tempo utilizado na coleta de traços no ar por trabalhador e em cada atividade. \\
\hline \multicolumn{1}{c}{ Atividade (processo) } & $\begin{array}{c}\text { Trabalhador } 1 \\
\text { Tempo (minutos) }\end{array}$ & $\begin{array}{c}\text { Trabalhador } 2 \\
\text { Tempo (minutos) }\end{array}$ \\
\hline Desengraxe (soda cáustica) & 10 & 10 \\
Jateamento (microesferas de vidro) & 15 & 15 \\
Fosfatização (fosfato de manganês) & 2 & 3 \\
Pintura (prime e tinta a óleo) & 3 & 3 \\
Solda (eletrodo de manganês) & 5 & - \\
\hline
\end{tabular}

Tabela 2. M onitoramento do ar na oficina de tratamento superficial.

\begin{tabular}{|c|c|c|c|c|}
\hline \multirow[t]{2}{*}{ Atividade } & \multicolumn{2}{|c|}{ Trabalhador 1 (T1) } & \multicolumn{2}{|c|}{ Trabalhador 2 (T2) } \\
\hline & {$[\mathrm{Pb}]\left(\mu \mathrm{gm}^{-3}\right)$} & {$[\mathrm{Mn}]\left(\mu \mathrm{g} \mathrm{m}^{-3}\right)$} & {$[\mathrm{Pb}]\left(\mu \mathrm{g} \mathrm{m}^{-3}\right)$} & {$[\mathrm{Mn}]\left(\mu \mathrm{g} \mathrm{m}^{-3}\right)$} \\
\hline Desengraxe & $2,0 \pm 1,4$ & $1,0 \pm 0,5$ & $\leq 0,5$ & $1,5 \pm 0,5$ \\
\hline Jateamento & $\leq 0,3$ & $2,0 \pm 0,3$ & $\leq 0,3$ & $0,7 \pm 0,3$ \\
\hline Fosfatização & $\leq 2,5$ & $27,5 \pm 2,5$ & $\leq 1,7$ & $115,0 \pm 1,7$ \\
\hline Pintura & $\leq 1,7$ & $3,3 \pm 1,7$ & $313,3 \pm 3,3$ & $6,7 \pm 1,7$ \\
\hline Solda & $4, \overline{5} \pm 0,4$ & $951,0 \pm 13,0$ & - & - \\
\hline
\end{tabular}

[Pb]: concentração de chumbo no ar; [M n]: concentração demanganês no ar. 
Os resultados mostram que as atividades de pintura e solda apresentaram concentrações acima das recomendadas pela ACGIH para chumbo e manganês, respectivamente. Por outro lado, os teores de manganês também se elevaram durante a fosfatização, o que já era esperado pelo uso do fosfato de manganês. Entretanto, quando se leva em conta que os TLV-TWA são relativos a oito horas de trabal ho e que as atividades foram monitoradas por, no máximo, quinze minutos, a extrapolação dos tempos de execução para cada atividade resulta em valores acima daquel es recomendados pela ACGIH para ambos os metais na fosfatização, pintura e solda realizadas pelos dois trabalhadores. Os resultados extrapolados não superam os limites apenas no jateamento e desengraxe com ambos os trabalhadores.

Por outro lado, Aizenberg e colaboradores ${ }^{15}$ encontraram valores de TWA 250, 6 , e 5 vezes superior ao limite de exposição permitido (PEL) para o cádmio, chumbo, cromo hexavalente, respectivamente, no estudo que investigou a exposição a metais dos trabal hadores que realizaram decapagem abrasiva em quatro bases da força aérea americana. Tal fato ressalta a importância dos equipamentos e processos de trabal ho quando se lida com substâncias tóxicas. 0 equipamento utilizado no jateamento possuía um processo de filtragem do ar exalado, o que mitigava a disseminação do particulado no ambiente de trabalho.

A diferença encontrada na concentração de manganês entre a atividade de fosfatização realizada pelos trabalhadores 1 e 2 pode ser decorrente das condições de ventilação e das posturas individuais durante a execução da atividade. De qualquer forma, isso indica que esses trabalhadores estão sujeitos a uma exposição el evada durante essa atividade, uma vez que a executa- ram por apenas, no máximo, três minutos.

A elevada concentração de chumbo encontrada na pintura com tinta a óleo realizada pelo trabalhador 2 sugere que a tinta utilizada nesse processo possui um alto teor de chumbo em sua composição. $\mathrm{Na}$ Tabela 2, observa-se ainda que também o teor de manganês nesta tinta é mais elevado, visto que a concentração encontrada durante a realização desta atividade foi o dobro daquela encontrada com 0 trabalhador 1 . Assim, pode-se entender o motivo pelo qual a concentração de $\mathrm{Mn}$ no ar foi 2,86 vezes maior, durante 0 jateamento feito pelo trabalhador 1 , do que esta mesma atividade desenvolvida pelo trabalhador 2, pois este último executava a pintura enquanto 0 outro realizava o jateamento.

$\mathrm{Na}$ atividade de solda, cujo eletrodo contém manganês, as concentrações desse metal no ar atingem valores elevadíssimos, caracterizando-se como uma atividadeextremamenteinsalubre. Esse resultado concorda com os achados de Wang e colaboradores ${ }^{9}$, que encontraram concentrações elevadas de manganês na saliva de soldadores.

Já os valores de referência utilizados para chumbo e manganês nos fluidos biológicos se referem àquel es encontrados na comunidade européia ${ }^{22}$, com Pb-S variando de 4,0 a $27,6 \mu \mathrm{g} \mathrm{dL}^{-1}$, enquanto que a faixa para $\mathrm{Pb}-\mathrm{U}$ é de 1,2 a $2,7 \mu \mathrm{g}$ $\mathrm{dL}^{-1}$. Em relação ao manganês, a variação da concentração é de 7,1 a 10,5 $\mathrm{g} \mathrm{L}^{-1}$ para sangue e de 0,12 a $1,9 \mu \mathrm{g} \mathrm{L}^{-1}$ para a urina. A N R-7, da legislação brasileira, só estabelece limites para chumbo em sangue, sendo o valor de referência até $40,0 \mu \mathrm{g}$ $\mathrm{dL}^{-1}$, enquanto o índicebiológico máximo permitido $^{30}$ (IBM P) é de $60 \mu \mathrm{g} \mathrm{dL}^{-1}$. A Tabela 3 mostra os resultados encontrados no monitoramento biológico de chumbo e manganês.

O bserva-seque os níveis destes metais no sangue ena urina se encontram dentro da faixa esta-

Tabela 3. Monitoramento biológico dos trabalhadores da oficina de tratamento superficial.

\begin{tabular}{lcccc}
\hline Trabalhador & $\mathrm{Pb}-\mathrm{S}\left(\mu \mathrm{g} \mathrm{dL}^{-1}\right)$ & $\mathrm{Pb}-\mathrm{U}\left(\mu \mathrm{gdL}^{-1}\right)$ & $\mathrm{Mn}-\mathrm{S}\left(\mu \mathrm{g} \mathrm{L}^{-1}\right)$ & $\mathrm{Mn}-\mathrm{U}\left(\mu \mathrm{g} \mathrm{L}^{-1}\right)$ \\
\hline $\mathrm{A}(\mathrm{T} 2)$ & $6,9 \pm 0,1$ & $0,9 \pm 0,4$ & $4,43 \pm 0,40$ & $1,20 \pm 0,09$ \\
B & $8,8 \pm 0,8$ & $0,5 \pm 0,3$ & $5,96 \pm 0,41$ & $2,70 \pm 0,19$ \\
C & $5,8 \pm 0,3$ & $0,5 \pm 0,3$ & $4,50 \pm 0,40$ & $2,95 \pm 0,03$ \\
D & $4,6 \pm 0,1$ & $0,6 \pm 0,3$ & $4,34 \pm 0,47$ & $3,85 \pm 0,07$ \\
E & $6,7 \pm 0,1$ & $0,5 \pm 0,2$ & $5,62 \pm 0,34$ & $0,87 \pm 0,15$ \\
F (T1) & $4,9 \pm 0,1$ & $0,3 \pm 0,2$ & $6,80 \pm 0,14$ & $2,36 \pm 0,01$ \\
G & $3,6 \pm 0,1$ & $0,5 \pm 0,2$ & $6,87 \pm 0,59$ & $0,31 \pm 0,03$ \\
H & $10,4 \pm 0,4$ & $0,6 \pm 0,3$ & $7,50 \pm 0,33$ & $1,22 \pm 0,01$ \\
I & $3,4 \pm 0,2$ & $0,4 \pm 0,2$ & $6,68 \pm 0,17$ & $1,02 \pm 0,01$ \\
\hline
\end{tabular}


belecida para os valores de referência adotados, com exceção dos trabalhadores B, C, D e F, cujos resultados para $\mathrm{Mn}-\mathrm{U}$ se encontram acima do limite. Entretanto, como a contaminação fortuita por este metal é extremamente fácil de acontecer, estes níveis devem ser vistos de forma cuidadosa.

Por outro lado, o monitoramento do ar da unidade detrabalho mostrou a existência decontaminação no ambiente e $45 \%$ dos trabalhadores avaliados apresentaram concentrações de manganês em urina acima do valor de referência, de modo que se pode dizer que a exposição existe, porém, fica difícil precisar em que grau. Caso o valor de referência $\left(0,97\right.$ a 1,07 $\left.\mu \mathrm{g} \mathrm{L}^{-1}\right) \mathrm{da}$ Agency for Toxic Substances and Disease Registry $(\text { ATSDR })^{21}$, órgão do serviço de saúde do governo norte-americano, para $\mathrm{M} \mathrm{n}$-U seja levado em consideração, este percentual de trabalhadores expostos passa para $67 \%$, o que ratifica a idéia de exposição ao metal.

A análise dos resultados de manganês em sangue ( $\mathrm{Mn}$-S) mostra que os sujeitos $\mathrm{H}(7,50 \pm 0,33$ $\left.\mu \mathrm{g} \mathrm{L}^{-1}\right)$ e $\mathrm{G}\left(6,87 \pm 0,59 \mu \mathrm{g} \mathrm{L}^{-1}\right)$ foram os que apresentaram os níveis mais elevados. Entretanto, ambos ainda se encontram dentro da faixa de 7,1 a $10,5 \mu \mathrm{g} \mathrm{L}^{-1}$, adotada como referência. Quando se compara os val ores obtidos para $\mathrm{M}$ n-S com aqueles estabelecidos pela ATSD R ${ }^{21}$, observa-se que todos os sujeitos também se encontram dentro do intervalo de 4 a $14 \mu \mathrm{g} \mathrm{L}^{-1}$. Esses resultados estão compatíveis com os achados de Ellingsen e colaboradores $^{34}$, pois estão abaixo dos valores encontrados, por eles, para 96 soldadores quesão trabal hadores sabidamente expostos ao metal em questão ( $\mathrm{Mn}$-S em torno de 8,6 $\mu \mathrm{g} \mathrm{L}^{-1}$ ).

Quanto ao chumbo, apesar dos valores de referência atualmenteutilizados ainda serem elevados e dos resultados encontrados por Paolielo e colaboradores ${ }^{35}$, que indicam que numa população brasileira urbana os valores de referência para chumbo no sangue variam de 2,4 a 16,6 $\mu \mathrm{g}$ $\mathrm{dL}^{-1}$ (média +2 desvios padrão), sabe-sequeconcentrações de chumbo no sangue entre 5 e $10 \mu \mathrm{g}$ $\mathrm{dL}^{-1}$ já sugerem a existência de al gum tipo de exposição ${ }^{36}$. N este sentido, a observação dos níveis de $\mathrm{Pb}$-S encontrados mostra que os indivíduos A, B, C, E e H se encontram expostos a baixos níveis de chumbo, significando uma exposição ambiental recente em $56 \%$ dos trabalhadores avaliados.

A concentração do chumbo na urina ( $\mathrm{Pb}-\mathrm{U}$ ) é de uso limitado e tem sido aplicada como teste de exposição na saúde ocupacional, uma vez quea medida deste parâmetro reflete exposição atual ${ }^{25}$. A urina é um indicador de exposição potencial- menteútil; porém, arelação existenteentreo chumbo no sangue ena urina ainda não é perfeitamente compreen dida ${ }^{26}$. A observação dos níveis de chumbo encontrados na urina dos trabalhadores mostra que todos os resultados se encontram dentro da faixa de concentração adotada como referência.

$\mathrm{Na}$ anamnese ocupacional, não foi detectada nenhuma relação da atividade laborativa com qualquer sintoma comum em indivíduosintoxicados por chumbo e manganês. De igual forma, não foi relatado sintoma comum que afete os trabal hadores desta oficina e que também possa estar relacionado com a exposição ocupacional ao chumbo e manganês. No entanto, al guns sujeitos expuseram que já sentiram irritação na garganta quando estavam sem máscaras e próximos aos tanques de banho.

$\mathrm{O}$ trabal hador $\mathrm{H}$ já realizou tratamento antialérgico nas unhas da mão, que caíram quando trabal hava em outra seção, realizando montagem elubrificação de armamento. A pesar de trabalhar há apenas três anos na oficina de tratamento superficial, nele foi encontrada a maior concentração de $\mathrm{Pb}-\mathrm{S}$. Pode-se sugerir que este resultado esteja relacionado àquela atividade exercida anteriormente, sem, contudo, esquecer da importância da constituição genética na determinação da vulnerabilidade individual ${ }^{25}$.

Com relação ao nível de consciência da importância de se utilizar os EPI previstos, há unanimidade em admitir a necessidade do uso de tais equipamentos para evitar riscos à saúde do trabalhador. Porém, apesar de reconhecer a importância do uso do EPI, a maioria dos trabaIhadores afirmou possuir conhecimento superficial a respeito dos produtos químicos manipulados e seus efeitos nocivos à saúde. Os trabalhadores relataram a existência de uma comissão interna para a prevenção de acidentes (CIPA) na organização militar em questão.

As características da oficina de tratamento superficial proporcionam espaço amplo e bem ventilado, diminuindo a exposição ocupacional aos vapores, pós e aerossóis tóxicos provenientes do processo de trabalho. Outro aspecto considerado relevante é a variabilidade da demanda, alternando períodos de considerável e pequena produção. Esta variação possibilita que, nos períodos de baixa produtividade, haja uma significativa diminuição da exposição dos trabaIhadores. Entretanto, essas pausas não são regulares e não têm por finalidade essa redução, somente acontecem para atender à demanda. De forma análoga, podem ocorrer longos períodos 
com produção contínua, o que resulta em maior exposição ocupacional dos trabalhadores.

\section{Conclusão}

0 chumbo é um dos contaminantes ambientais mais comuns e não possui função fisiológica conhecida no organismo, diferente do manganês, que participa de processos metabólicos no organismo humano. Entretanto, esteúltimo, quando encontrado em níveis elevados, é neurotóxico. Sendo assim, a presença destes metais no organismo humano deve ser monitorada, principalmente no caso de exposição ocupacional.

Entre as atividades avaliadas na oficina de tratamento superficial, o desengraxe e 0 jateamento são osúnicosa não oferecer riscos decontaminação pelos metais monitorados. Assim, o processo de fosfatização oferece riscos à saúde dos trabalhadores, ainda que o monitoramento biológico dos trabalhadores tenha indicado que os níveis dos indicadores de dose interna estão dentro de parâmetros legais, internacionalmente aceitáveis. As atividades de pintura esolda são as que oferecem maior risco ocupacional em relação ao chumbo e manganês, respectivamente.

A análise dos resultados encontrados para o manganês indica que não se deve utilizar apenas um indicador de dose interna para avaliação de exposição a este metal. A avaliação em relação a esse metal deve ser realizada pelo conjunto de resultados, utilizando os dois indicadores de exposição e, se possível, também o monitoramento ambiental. 0 chumbo em urina também requer uma leitura cautelosa, pois não tem uma correlação direta com o chumbo em sangue, em baixos níveis de concentração.

\section{Colaboradores}

EB N eves e NM Junior trabalharam na concepção, na metodologia, na coleta dos dados e na redação final; M FR M oreira colaborou na metodologia, análise dos dados e na redação final. 


\section{Referências}

1. Tambellini AT, Câmara VM . A temática saúde e ambiente no processo de desenvolvimento do campo da saúde coletiva: aspectos históricos, conceituais e metodológicos. Cien Saude Colet 1998; (2):47-59.

2. Brasil. M inistério da Saúde. Doenças relacionadas ao trabalho: manual de procedimentos para os serviços de saúde [Série $A$. Normas e $M$ anuais Técnicos $n^{\circ}$ 114]. Brasília: Ministério da Saúde; 2001.

3. Fundação Nacional da Saúde. Sistema Nacional de Vigilância Ambiental em Saúde. Brasília: Fundação Nacional da Saúde; 2001.

4. Freitas CM, Porto M FS, Moreira JC, Pivetta F, Machado JMH, Freitas NBB, Arcuri AS. Chemical safety, health, and environment: prospects for governance in the Brazilian context. Cad Saude Publica [periódico na Internet]. 2002 [acessado 2007 nov 19]; 18(1):[cerca de 8 p.]. Disponível em: http:// www.scielo.br/scielo.php?script $=$ sci_arttext\& pid $=S 0102-311 X 2002000100025 \&$ lng $=$ en $\&$ nrm $=$ iso

5. Neves EB. Occupational risk management in the Brazilian army: normative and practical aspects. Cad Saude Publica 2007; 23(9):2127-2133.

6. May LM, Weese $C$, Ashley DL, Trump DH, Bowling $C M$, Lee AP. The recommended role of exposure biomarkers for the surveillance of environmental and occupational chemical exposures in military deployments: Policy considerations. M ilitary M edicine 2004; 169(10):761-767.

7. Selden A, Nygren $M$, Kvarnlof A, Sundell K, Spangberg $\mathrm{O}$. Biological Monitoring of Hexachloroethane. International Archives of 0 ccupational and Environmental Health 1993; 65(1):111-114.

8. May LM, Heller J, Kalinsky V, Ejnik J, Cordero S, Oberbroekling KJ, Long TT, M eakim KCE, Cruess $D$, Lee AP . M ilitary deployment human exposure assessment: U rine total and isotopic uranium sampling results. Journal of Toxicology and Environmental H ealth 2004; 67(8):697-714.

9. Wang $D X, D u X Q$, Zheng W. Alteration of saliva and serum concentrations of manganese, copper, zinc, cadmium and lead among career welders. Toxicology Letters 2008; 176(1):40-47.

10. Neves EB, Soalheiro M. A proteção auditiva utilizada pelos militares do Exército Brasileiro: há efetividade? Cien Saude Colet [periódico na Internet] 2008 [acessado 2008 jun 16]; [cerca de 15 p.] Disponível em: http://www.cienciaesaudecoletiva.com.br

11. Kuronen P, Toppila E, Starck J, Paakkonen R, Sorri $M J$. Modelling the risk of noise-induced hearing loss among military pilots. International Journal of Audiology 2004; 43(2):79-84.

12. Booher LE. Lead exposure in a ship overhaul facility during paint removal. Am Ind H yg Assoc J. 1988; 49(3):121-127.

13. Zedd HC, Walker YP, Hernandez JE, Thomas RJ. Lead exposures during shipboard chipping and grinding paint-removal operations. Am Ind $\mathrm{Hyg}$ Assoc J. 1993; 54(7):392-396.

14. Sussell A, Hart C, Wild D, Ashley K. An evaluation of worker lead exposures and cleaning effectiveness during removal of deteriorated lead-based paint. Appl Occup Environ Hyg. 1999; 14(3):177-185.
15. Aizenberg V, England E, Grinshpun S, Willeke K, Carlton G. Metal exposure among abrasive blasting workers at four U.S. Air Force facilities. Appl O ccup Environ Hyg. 2000; 15(10):766-772.

16. Silva RB. 0 Licenciamento ambiental das oficinas de tratamento superficial nas organizações militares de manutenção do exército brasileiro [trabalho de conclusão de curso de Aperfeiçoamento em Operações Militares]. Rio de Janeiro: Escola de Aperfeiçoamento de Oficiais; 2004.

17. Almeida RS. Produção para Fosfatização \& Oxidação. Rio de Janeiro: Batalhão de Manutenção de Armamento; 2005.

18. Azevedo FA, Chasin AAM. M etais: gerenciamento da toxicidade. São Paulo: Atheneu; 2003.

19. U.S. Public Health Service. Toxicological Profile for Manganese. Atlanta: , Agency For Toxic Substances and Disease Registry; 2000.

20. Tsalev DL, Zaprianov ZK. Atomic Absorption Spectrometry in Occupational and Environmental $\mathrm{H}$ ealth Practice. $2^{\text {nd }}$ ed. Florida: CRC Press; 1985.

21. Moreira FR, Pivetta F. M anganese Determination in Air, Blood and Urine, using $\mathrm{Mg}\left(\mathrm{NO}_{3}\right)_{2}$ as Modifier and "In Situ" Decontamination by Graphite Furnace Atomic Absorption Spectrometry. Atomic Spectroscopy 1996; 19 (4):24-30.

22. Minoia C, Sabbioni E, Apostoli P, Pietra R, Pozzoli L, Galirini M, Nicolau G, Alessio L, Capodaglio E. Trace elements Reference Values in Tissues from Inhabitants of the European Community. The Science of the Total Environment 1990; 95:89-105.

23. Quitério SL, M oreira FR, Silva CRS, Arbilla G, Araújo UC, Mattos RCOC. Avaliação da poluição ambiental causada por particulado de chumbo emitido por uma reformadora de baterias na cidade do Rio de Janeiro, Brasil. Cad Saude Publica 2006; 22(9):1817-1823.

24. Moreira FR, Moreira JC. A importância da análise de especiação do chumbo em plasma para a avaliação dos riscos à saúde. Química N ova 2004; 27(2):251-260.

25. M oreira FR, Moreira JC. A cinética do chumbo no organismo humano e sua importância para a saúde. Cien Saude Colet [periódico na Internet]. 2004 [acessado 2007 set 04]; 9(1):[cerca de 15 p]. Disponível em: http://www.scielo.br/scielo.php?script=sci_ arttext \&pid=S1413-81232004000100017\&lng=pt $\& n r m=i s o$

26. Sakai T, Ushio K, Ikeya Y. M obilized plasma lead as an index of body burden and its relation to the heme-related indices. Ind Health. 1998; 36:240-246.

27. Cordeiro R, Lima Filho EC, Salgado PET, Santos CO, Constantino L, Malatesta M LLS. Neurological disturbances in workers with low levels of lead in the blood: II-Neuropsychological disorders. Rev. Saude Publica 1996; 30(4): 358-363.

28. Haber, L. T.; Maier, A. Scientific Criteria Used for the Development of Occupational Exposure Limits for $M$ etals and Other M ining-Related Chemicals Regul. Toxicol. Pharm. 2002; 36(3): 262-279. 
29. Norma Regulamentadora $n=15$ (NR 15) - Atividades e operações insalubres. [site da Internet]. [acessado 2007 set 13]. Disponível em: http://www.mte.gov.br/ legislacao/normas_regulamentadoras/nr_15.pdf

30. Toxikon. [site da Internet]. [acessado 2007 set 13]. Disponível em: http://www.toxikon.com.br/qlnr7. html\# NICIO

31. Fortunato CE. Boletim Técnico no 01/04 - Processo de fosfatização de armamento leve. Rio de Janeiro: Arsenal de Guerra do Rio de Janeiro; 2004.

32. Barceloux DG. M anganese. [acessado 2007 set 13]. Disponível em: http://cat.inist.fr/?aM odele=afficheN $\&$ cpsidt $=1860422$

33. National Institute of Standards and Technology. Standard Reference M aterials Program. M aterial Safety Data Sheet. [acessado 2007 set 13]. Disponível em: https://srmors.nist.gov/msds/view_msds2pdf.cfm? msds $=2584$

34. Ellingsen DG, Dubeikovskaya L, Dahl K, Chashchin M, Chashchin V, Zibarev E, Thomassen Y. Air exposure assessment and biological monitoring of manganese and other major welding fume components in welders. J Environ M onit. 2006; 8(10):1078-1086.

35. Paolielo M M B, Gutierrez PR, Turini CA, M atsuo T, Mazzaroba L, Barbosa DS, Alvarenga ALP, CarvaIho SRQ, Figueiroa GA, Leite VGM , Gutierrez AC, Nogueira KB, Inamine WAS, Zavatti AM. Valores de referência para plumbemia em população urbana. Rev. Saude Publica 1997; 31(2):144-148.

36. Moreira FR, M ello M, Gomes RA, N eves EB. The feasibility of using lead in urine as a biological exposure indicator. XI International Congress of Toxicology, 2007; M ontreal, Canadá.

Artigo apresentado em 22/10/2007

Aprovado em 30/07/2008 